[Agr. Biol. Chem., Vol. 33, No. 4, p. 514 520, 1969]

\title{
Production of Nucleic Acid-Related Substances by Fermentative Processes
}

\section{Part XXIII. Derivation of IMP-Producing Mutants of Brevibacterium ammoniagenes}

\author{
By Masanaru Misawa, Takashi Nara and Shukuo KInoshita \\ Tokyo Research Laboratory, Kyowa Hakko Kogyo Co., Ltd., Machida-shi, Tokyo
}

Received August 19, 1968

\begin{abstract}
In attempts to obtain GMP producing strains, Brevibacterium ammoniagenes was treated with UV, N.T.G. or D.E.S. as a mutagen. Adenine-guanine requiring mutants were obtained from an adenine-requiring mutant of Brev. ammoniagenes, KY 3482-9 and two of them, presumably adenine-xanthine requiring mutants, were then reverted to mutants which required only adenine for their growth.

Although these revertants were not able to accumulate a copious amount of GMP, most of them and of adenine-guanine requiring mutants produced larger amounts of IMP than the parent adenine-requiring strain.

Effects of $\mathrm{Mn}^{2+}$ and purine bases in the medium on IMP production by these mutants were examined and IMP productivities of these mutants were compared with the parent strain under optimal conditions.

These mutagenic treatments were thus proved to be effective for the increase of de novo IMP production by Brev. ammoniagenes mutants.
\end{abstract}

Demain et al. ${ }^{11}$ reported that a revertant derived from an adenine and xanthine auxotroph of Corynebacterium glutamicum accumulated GMP in a fermentation medium. It was suggested that IMP dehydrogenase in the revertant might be desensitized against the inhibition by GMP.

In order to obtain GMP-accumulating strains, Brev. ammoniagenes was selected as a parental strain for mutation, since the organism was previously shown capable of produc-

Abbreviation. IMP: 5'-Inosine monophosphate, GMP: 5'-Guanosine monophosphate, XMP: 5'-Xanthosine monophosphate, $\mathrm{Hx}$ : Hypoxanthine, Ad: Adenine, Gu: Guanine, Xa: Xanthine, S.AMP: Adonylosuccinate, DCW: Dried cell weight $(\mathrm{mg} / \mathrm{ml}$ ), N.T.G.: N-methyl-N'-nitro-N-nitrosoguanidine, D.E.S.: Diethyl sulfate, UV: Ultraviolet.

1) A. L. Demain, M. Jackson, R. A. Vitali, D. Hendlin and T. A. Jacob, Appl. Microbiol., 14, 821 (1966). ing a large amount of IMP through de novo or salvage ${ }^{31}$ synthesis.

Numerous mutants of Brev. ammoniagenes were obtained by induced mutation techniques. None of them produced a copious amount of GMP, but many mutants derived from an adenine-requiring mutant of Brev. ammoniagenes KY 3482, one of natural isolates, accumulated larger amounts of IMP and/or XMP in their culture fluid.

These mutagenic treatments were thus found more effective for obtaining a strain capable of accumulating larger amounts of IMP in the medium.

2) T. Nara, M. Misawa and S. Kinoshita, Agr. Biol. Chem., 31, 1351 (1967).

3) T. Nara, M. Misawa and S. Kinoshita, ibid., 32, 561 (1968). 


\section{MATERIALS AND METHODS}

Microorganisms used. An adenine-requiring mutant, KY 3482-9, derived from Brevibacterium ammoniagenes KY 3482 by irradiation with ultraviolet light 4 ? was used as a parent strain to obtain mutants. Strain $\mathrm{KY} 3482$, one of the natural isolates, is able to accumulate a large amount of IMP from hypoxanthine in the medium.4!

Media. Three media were used: (1) a nutrient medium (" $N$ " medium) consisting of glucose $2 \%$, yeast extract $0.5 \%$, peptone $1.00^{\circ}$, meat extract $1.0 \%^{\circ}$, and $\mathrm{NaCl} 0.25 \%$, (2) a complete medium ("C'" medium) consisting of glucose $1.0 \% \%\left(\mathrm{NH}_{4}\right)_{2} \mathrm{SO}_{4} 0.4 \%, \mathrm{~K}_{2} \mathrm{HPO}_{4}$ $0.1 \%, \mathrm{MgSO}_{4} \cdot 7 \mathrm{aq} 0.03 \%$, casamino acids "Nissan" $0.25 \%$, thiamine. $\mathrm{HCl} 5 \mathrm{mg} /$ liter, Ca-D-pantothenate $10 \mathrm{mg} /$ liter, trace elements $1.0 \mathrm{ml} /$ liter, urea $0.1 \%$, L-cysteine $50 \mathrm{mg} /$ liter, L-tryptophan $50 \mathrm{mg} /$ liter, biotin $30 \mu \mathrm{g} /$ liter, adenine $30 \mathrm{mg} / \mathrm{liter}$, and guanine $30 \mathrm{mg} /$ liter and (3) a minimal medium (" $M$ " medium) consisting of the same composition as " $\mathrm{C}$ " medium with the exception of purine bases.

$\mathrm{pH}$ of each medium was adjusted to 7.3 with $5 \mathrm{~N}$ $\mathrm{NaOH}$ and $2 \%$ of agar were added for a solid medium.

For the examination of nucleotides fermentation, a seed medium, whose composition is the same as " $\mathrm{N}$ " medium, and two fermentation media were used: (1) natural fermentation medium (" $\mathrm{Y}$ " medium) consisting of glucose $10.0 \%, \mathrm{KH}_{2} \mathrm{PO}_{4} 1.0 \%, \mathrm{~K}_{2} \mathrm{HPO}_{4}$ $1.0 \%, \mathrm{MgSO}_{4} .7 \mathrm{aq} 1.0 \%, \mathrm{CaCl}_{2} .2 \mathrm{aq} 0.01 \%$, yeast extract $1.0 \%$, and biotin $30 \mu \mathrm{g} /$ liter and (2) a semidefined medium (" $D$ " medium) consisting of glucose $10.0 \%, \mathrm{KH}_{2} \mathrm{PO}_{4} 1.0 \%, \mathrm{~K}_{2} \mathrm{HPO}_{4} 1.0 \%, \mathrm{MgSO}_{4} \cdot 7 \mathrm{aq}$ $1.0 \%, \mathrm{CaCl}_{2} \cdot 2 \mathrm{aq} 0.01 \%$, meat extract $0.2 \%$, thiamine. HCl $5 \mathrm{mg}$ /liter, Ca-D-pantothenate $10 \mathrm{mg} /$ liter, biotin $30 \mu \mathrm{g} /$ liter, and $\mathrm{MnSO}_{4} \cdot 4 \mathrm{aq} 40 \mu \mathrm{g} /$ liter.

$\mathrm{pHs}$ of both fermentation media were adjusted to 8.2 with $5 \mathrm{~N}-\mathrm{NaOH}$, and $0.6 \%$ of urea (autoclaved separately) was supplemented to both media before inoculation.

Detailed fermentation techniques were reported previously. ${ }^{5}$

Induction of mutation. To obtain adenine and guanine doubleless mutants from an adenineless mutant (KY 3482-9) of Brev. ammoniagenes, UV, N-

4) T. Nara, unpublished data.

5) K. Nakayama, T. Suzuki, Z. Sato and S. Kinoshita, J. Gen. Appl. Microbiol., 10, 133 (1964).
methyl-N'-nitro-N-nitrosoguanidine (abbreviated as N.T.G.) and diethyl sulfate (D.E.S.) were used as mutagens. Revertants which required adenine alone were derived spontaneously from the adenine-guaninerequiring mutants, KY $3482-9-26$ and KY 3482-954 .

Mutation techniques were the same as those of Lichstein et al.6) KY 3482-9 was incubated in " $M$ " medium for 1 day at $30^{\circ} \mathrm{C}$, harvested by centrifugation, suspended in and irradiated with UV light (Toshiba Electric Co. Ltd., GL-15) or treated with N.T.G. or D.E.S. In the case of N.T.G. treatment, cells were mixed with $100 \mu \mathrm{g} / \mathrm{ml}$ of N.T.G. solution for 15 or $30 \mathrm{~min} .{ }^{7}$ Treatments with D.E.S. solution were made by the modified method of Udagawa. ${ }^{8}$ A reaction mixture for D.E.S. treatment consisted of cell suspension ( $c a .10^{9}$ cells $/ \mathrm{ml}$ ) $0.5 \mathrm{ml}, \mathrm{M} / 10$ phosphate buffer (pH 7.0) $4.3 \mathrm{ml}$, and $16 \%$ D.E.S. solution in ethanol $0.2 \mathrm{ml}$. Reaction mixture was incubated for 1,2 and $4 \mathrm{hr}$ at $30^{\circ} \mathrm{C}$.

The cells treated with each mutagen were washed twice with saline and spread on " $\mathrm{N}$ " agar medium directly, or incubated in " $\mathrm{C}$ " liquid medium overnight and transferred into " $\mathrm{M}$ " liquid medium containing $100 \mathrm{u} / \mathrm{ml}$ of penicillin $\mathrm{G}$ for enrichment. ${ }^{9}$

Mutants were isolated by replica method from " $\mathrm{C}$ " and "M" agar plate media.

Analytical method. Determination of IMP, XMP and purine bases was made by the paperchromatography with a solvent system of isobutyric acid, $1 \mathrm{~N}$-ammonia, and acetic acid $(10: 5: 1)$. Yields of IMP and XMP were expressed as $\mathrm{mg} / \mathrm{ml}$ of IMP $\cdot 2 \mathrm{Na} \cdot 7 \frac{1}{2} \mathrm{H}_{2} \mathrm{O}$ and of XMP.2Na, respectively. Those of purine bases were shown as mg per ml of the broth.

Glucose and bacterial growth (shown as D.C.W.) were determined by the same methods as reported previously. 10 r

Materials used. Casamino acids (vitamin-free acid hydrolyzed casein) were obtained from Nissui Seiyaku Co., Tokyo; diethyl sulfate was purchased from Wakō Jyunyaku Co. Ltd., Tokyo, and N.T.G. was from

6) H.C. Lichstein and E. L. Oginsky, "Experimental Microbial Physiology", W. H. Freeman Co., p. $72(1965)$.

7) E. A. Adelberg, M. Mandel and G. C. C. Chen, Biochem. Biophys. Res. Comm., 18, 788 (1965).

8) K. Udagawa, a personal communication.

9) B. D. Davis, J. Am. Chem. Soc., 70, 4267 (1948).

10) M. Misawa, T. Nara, K. Udagawa, S. Abe and S. Kinoshita, Agr. Biol. Chem., 28, 688 (1964). 
Aldrich Chem. Co. Inc., Milwaukee, Wis., U.S.A.

\section{RESULTS}

Isolation of adenine-guanine requiring mutants from an adenine requiring mutant

An adenine requiring mutant (KY 3482-9) of Brev. ammoniagenes KY 3482, one of natural isolates, accumulates a large amount of IMP in a culture medium. ${ }^{4)}$ To obtain adenineguanine requiring mutants, KY 3482-9 strain was treated with three kinds of mutagens.

The growth responses to purine bases of purine base requiring mutants obtained from KY 3482-9 are shown in Table I.

Table I. Growth Responses of Mutants TO PURINE BASES

\begin{tabular}{|c|c|c|c|c|}
\hline \multirow[t]{2}{*}{ Mutants } & \multicolumn{4}{|c|}{$\begin{array}{l}\text { Addition } \\
\text { Growth }\end{array}$} \\
\hline & $\mathrm{Ad} \cdot \mathrm{Hx}$ & $\mathrm{Gu} \cdot \mathrm{Ad}$ & $\mathrm{Gu} \cdot \mathrm{Hx}$ & none \\
\hline $\mathrm{Ad}^{-} \mathrm{Gu}$ & - & + & - & - \\
\hline $\mathrm{Ad}^{-}$(parent) & + & + & - & - \\
\hline $\mathrm{Gu}^{-}$ & - & + & + & - \\
\hline Pur- & + & + & + & - \\
\hline $\begin{array}{l}\text { Wild type or }+ \\
\text { Revertant }\end{array}$ & + & + & + & + \\
\hline $\begin{array}{l}+: \text { growth }- \text { : } \\
\text { Basal medium: } \\
\text { "N": Nutrient } \\
\text { Methods. Growth } \\
1 \text { day. }\end{array}$ & $\begin{array}{l}\text { no grov } \\
\text { "M" med } \\
\text { hedium o } \\
\text { n plate }\end{array}$ & $\begin{array}{l}\text { vth } \\
\text { dium (ag } \\
\text { lescribed } \\
\text { media w }\end{array}$ & $\begin{array}{l}\text { ar plate) } \\
\text { in Mater } \\
\text { as check }\end{array}$ & Is and \\
\hline
\end{tabular}

Strict adenine-guanine requiring mutants grow only on the " $M$ " medium supplemented with adenine and guanine, whereas non-strict purine auxotrophs are able to grow on the "M" medium supplemented with adenine and guanine, adenine and hypoxanthine, guanine and hypoxanthine, or hypoxanthine, but not on adenine or guanine alone. All of the mutants derived from KY 3482-9 were examined for their growth on those media and strict adenine-guanine mutants were isolated and stored on slant agar media.

The typical examples of mutations with
TABle II. TyPical EXAMPLES OF Mutation With THREE Mutagens To OBtaIN ADENINEGUANINE REQUIRING MUTANTS

$\begin{array}{lcll}\text { Mutagen } & \text { Conditions } & \begin{array}{c}\text { Killing } \\ \text { ratio }(\%)\end{array} & \begin{array}{c}\text { Mutation* } \\ \text { rate }(\%)\end{array} \\ \text { UV } & 51 \mathrm{~cm}, 3^{\prime} & 99.998 & 0.044 \\ \text { N.T.G. } & 100 \mu \mathrm{g} / \mathrm{ml}, 30^{\prime} & 66.40 & 0.318 \\ \text { D.E.S. } & 0.32 \%, 2 \mathrm{hr} & 99.46 & 2.11\end{array}$

* Mutation rate is expressed as the percentage of the number of strict adenine-guanine requiring mutants against that of isolated cells.

three mutagens are shown in Table II. D.E.S. was usually the most effective mutagen for obtaining adenine-guanine requiring mutants from KY 3482-9.

\section{Nucleotide productivity of adenine-guanine requir- ing mutants}

Adenine-guanine requiring mutants (545 strains) were incubated both in " $\mathrm{Y}$ " medium (see Materials and Method) and " $Y$ " supplmented with $1 \mathrm{mg} / \mathrm{ml}$ of $\mathrm{Mn}^{2+}$, for 5 days at $30^{\circ} \mathrm{C}$ and the kinds and yields of fermentation products were studied.

The results are shown in Tables III and IV.

As reported previously, in the presence of an excessive level of $\mathrm{Mn}^{2+}$ in the medium, IMP production was inhibited markedly, ${ }^{11}$ but XMP production was stimulated by guanineless mutants. ${ }^{12}$ However, several mutants were found to be stimulated IMP production in the " $\mathrm{Y}$ " medium containing

TABle III. Relations Between PRoducts AND POSSIBLE NUTRITIONAL ReQUIREMENTS

$\begin{array}{lcc}\quad \text { Products } & \text { No. of mutants } & \text { Requirements } \\ \text { XMP } & 262 & \mathrm{ad}^{-}, \mathrm{gu}^{-} \\ \text {IMP } & 117^{*} & \mathrm{ad}^{-}, \mathrm{Xa}^{-} \\ \text {XMP+IMP } & 156 & \mathrm{ad}^{-}, \mathrm{gu}^{-} \\ \text {None } & 10 & ?\end{array}$

* All of these mutants were phenotypically adenineguanine requiring strains.

11) T. Nara, M. Misawa and S. Kinoshita, Agr. Biol. Chem., 32, 1153 (1968).

12) M. Misawa, T. Nara, K. Udagawa, S. Abe and S. Kinoshita, ibid., 33, 370 (1969). 
Table IV. Nucleotide Productivity of Some Adenine-Guanine Requiring Mutants DERIVEd From KY 3482-9

\begin{tabular}{|c|c|c|c|c|c|c|c|}
\hline \multirow[b]{2}{*}{ Strains } & \multirow[b]{2}{*}{ Requirements } & \multirow[b]{2}{*}{ Mutagen } & \multicolumn{5}{|c|}{ 5-Day } \\
\hline & & & $\mathrm{pH}$ & $\begin{array}{c}\mathrm{DCW} \\
\mathrm{mg} / \mathrm{ml}\end{array}$ & $\begin{array}{c}\mathrm{IMP} \\
\mathrm{mg} / \mathrm{ml}\end{array}$ & $\underset{\mathrm{mg} / \mathrm{ml}}{\mathrm{Hx}}$ & $\begin{array}{c}\mathrm{XMP} \\
\mathrm{mg} / \mathrm{ml}\end{array}$ \\
\hline Parent* & $\mathrm{ad}$ & & 6.2 & 8.3 & 4.63 & 0.62 & 0 \\
\hline 2 & ad. gu (xa) & UV & 6.3 & 10.8 & 7.48 & 0.83 & 0 \\
\hline 26 & $" \prime$ & D.E.S. & 6.3 & 10.4 & 8.60 & 0.40 & 0 \\
\hline 28 & $"$ & $" 1$ & 6.2 & 9.7 & 7.93 & 0.64 & 0 \\
\hline 54 & " & N.T.G. & 6.2 & 10.3 & 8.78 & 0.34 & 0 \\
\hline 66 & " & $"$ & 6.1 & 8.9 & 8.55 & 0.65 & 0 \\
\hline 99 & " & " & 6.0 & 8.6 & 8.50 & 0.44 & 0 \\
\hline 207 & $" \prime$ & $"$ & 6.1 & 8.8 & 8.44 & 0.54 & 0 \\
\hline 402 & ad. gu & D.E.S. & 6.3 & 8.7 & 0.57 & 0.41 & 6.39 \\
\hline 527 & $"$ & 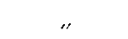 & 6.2 & 9.9 & 0.55 & 0.58 & 5.90 \\
\hline
\end{tabular}

Fermentation medium: " $D$ " medium supplemented with $150 \mu \mathrm{g} / \mathrm{ml}$ each of adenine and guanine was used for the IMP producting strains. "Y" medium supplemented with $4 \mathrm{mg} /$ liter of $\mathrm{MnSO}_{4}$. 4 aq was used for XMP producting strains.

* KY $3482-9$.

TABLE V. EFFEcts OF MEdIUM AND $\mathrm{Mn}^{2+}$ on IMP PRODUCTION BY KY $3482-9$ AND KY 3482-9-54

\begin{tabular}{|c|c|c|c|c|c|c|}
\hline \multirow[b]{2}{*}{ Strains } & \multirow[b]{2}{*}{ Medium } & & \multicolumn{4}{|c|}{ 5-Day } \\
\hline & & $\begin{array}{c}\mathrm{Mn}^{2+} \\
1 \mathrm{mg} / \text { liter }\end{array}$ & $\mathrm{pH}$ & $\begin{array}{l}\mathrm{DCW} \\
\mathrm{mg} / \mathrm{ml}\end{array}$ & $\begin{array}{l}\mathrm{IMP} \\
\mathrm{mg} / \mathrm{ml}\end{array}$ & $\begin{array}{c}\mathrm{Hx} \\
\mathrm{mg} / \mathrm{ml}\end{array}$ \\
\hline \multirow{2}{*}{ Parent $\left(\mathrm{ad}^{-}\right) \mathrm{KX} \quad 3482-9$} & $Y$ & $\overline{+}$ & $\begin{array}{l}5.9 \\
5.8\end{array}$ & $\begin{array}{l}10.0 \\
14.7\end{array}$ & $\begin{array}{l}3.10 \\
1.23\end{array}$ & $\begin{array}{l}2.37 \\
2.26\end{array}$ \\
\hline & D & $\bar{t}$ & $\begin{array}{c}6.2 \\
\prime \prime\end{array}$ & $\begin{array}{r}8.4 \\
13.4\end{array}$ & $\begin{array}{l}4.63 \\
0.92\end{array}$ & $\begin{array}{l}0.62 \\
1.11\end{array}$ \\
\hline \multirow{2}{*}{$\mathrm{KY} 3482-9-54\left(\mathrm{ad}^{-}, \mathrm{gu}^{-}\right)$} & $\mathrm{Y}$ & $\overline{+}$ & $\begin{array}{l}6.7 \\
6.2\end{array}$ & $\begin{array}{l}7.1 \\
8.3\end{array}$ & $\begin{array}{l}1.38 \\
2.20\end{array}$ & $\begin{array}{l}1.34 \\
2.95\end{array}$ \\
\hline & $\mathrm{D}$ & $\overline{+}$ & $\begin{array}{c}6.1 \\
\prime \prime\end{array}$ & $\begin{array}{l}10.2 \\
13.1\end{array}$ & $\begin{array}{l}8.78 \\
2.03\end{array}$ & $\begin{array}{l}0.34 \\
1.22\end{array}$ \\
\hline
\end{tabular}

" $Y$ " and "D" media described in Materials and Methods were supplemented with both adenine $150 \mu \mathrm{g} / \mathrm{ml}$ and guanine $150 \mu \mathrm{g} / \mathrm{ml}$.

excessive levels of $\mathrm{Mn}^{2+}$ KY 3482-9-54 is one of these strains as shown in Table $\mathrm{V}$.

From the results in Table III, it appears that the mutants accumulating XMP or XMP and IMP are the adenine-guanine doubleless mutants; namely, both S.AMP synthetase (EC 6.3.4.4) and XMP aminase (EC 6.3.5.2) of these mutants might be lost simultaneously. In contrast to these mutants, 117 strains accumulated only IMP and they seem to be blocked in two reactions which are catalyzed by S.AMP synthetase and IMP dehydrogenase, respectively. These mutants are probably adenine-xanthine requiring mutants. However, these mutants and a non-strict purineless mutants of $\mathrm{Br}$. ammoniagenes were not able to grow on the " $M$ " medium supplemented with adenine and xanthine, since it has been reported that the XMP-pyrophosphorylase of $\mathrm{Br}$. ammoniagenes was lacking or its activity was of low level. ${ }^{12 !}$

The IMP productivity of most of these 117 mutants was higher than that of the parent strain as shown in Table IV. This fact also supports that these strains were the adeninexanthine requiring mutants, since it is rea- 
sonable to suppose that the deficiency of IMP dehydrogenase (xanthine-less) in addition to that of S.AMP synthetase (adenine-less) would favor the enhancement of IMP accumulation. $^{131}$

\section{Optimal concentrations of adenine and guanine}

Optimal concentrations of adenine and guanine in the fermentation medium for the IMP production by an adenine-guanine (or strictly speaking, adenine-xanthine) requiring mutant, KY 3482-9-28, were compared with those by a parent strain, KY 3482-9. (Fig. I).

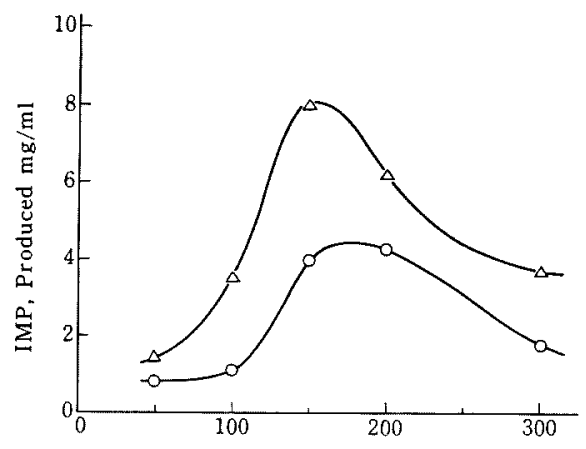

Adenine and guanine (each $\mu \mathrm{g} / \mathrm{ml}$ )

(A) " $\mathrm{D}$ " medium, $\mathrm{Mn}^{2+}$-deficient $\left(10 \mu \mathrm{g} \mathrm{Mn}{ }^{2+} / \mathrm{ml}\right)$.

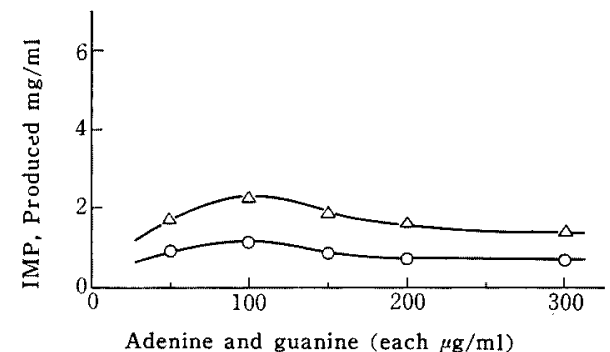

(B) "D" medium, $\mathrm{Mn}^{2+}$-excess (1000 $\left.\mu \mathrm{g} \mathrm{Mn}{ }^{2+} / \mathrm{ml}\right)$.

FIG. 1. Effect of Adenine and Guanine Levels on IMP Accumulation.

O-O KY 3482-9 (ad-).

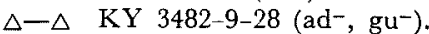

after 5 days cultivation.

13) A. L. Demain, M. Jackson, R. A. Vitali, D Handlin and T.A. Jacob, Appl. Microbiol., 13, 757 (1965).
By acquisition of guanine requirement, the optimal concentrations of both bases were lowered to $150 \mu \mathrm{g}$ of each base per $\mathrm{ml}$ from $200 \mu \mathrm{g} / \mathrm{ml}$ for an adenine-requiring mutant.

Inhibition of IMP production by an excess amount of $\mathrm{Mn}^{2+}$ with KY 3482-9-28 was lower than that with the parent strain.

\section{Reversion to adenine requiring mutant from adenine- guanine requiring mutant}

To obtain a mutant with altered IMP dehydrogenase, an adenine-guanine requiring mutant (adenine-xanthine requiring mutant, strictly speaking) was reverted to adeninerequiring mutants.

In these experiments two strains, KY 3482 9-26 and KY 3482-9-54 were selected as the parents since they had higher productivity of IMP.

Three hundred and twenty seven revertants were obtained spontaneously from these two strains and they were shown to have only adenine requirement.

Productivities of nucleotides by revertants

The adenine-requiring mutants (revertants)

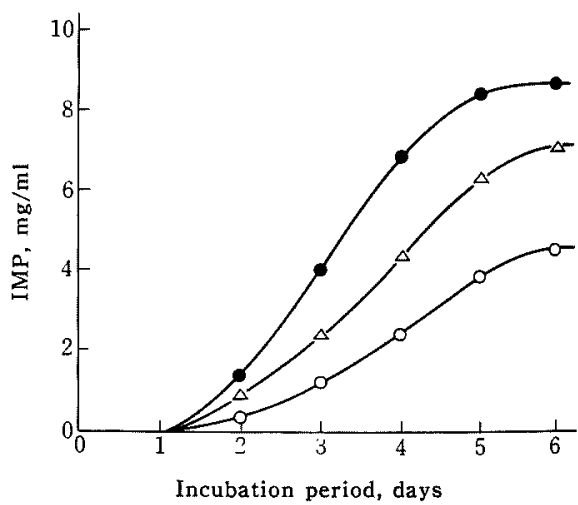

FIG. 2. IMP Productivities of Mutants.

Medium: " $D$ " medium.

O-O KY 3482-9 (ad-) ad $150 \mu \mathrm{g} / \mathrm{ml}$.

- KY 3482-9-54 (ad-. $\left.\mathrm{gu}^{-}\right)$ad $150 \mu \mathrm{g} / \mathrm{ml}$ and $\mathrm{gu} 150 \mu \mathrm{g} / \mathrm{ml}$.

$\triangle-\triangle$ KY 3482-9-54-252 (Revertant, ad-) ad $150 \mu \mathrm{g} / \mathrm{ml}$. 


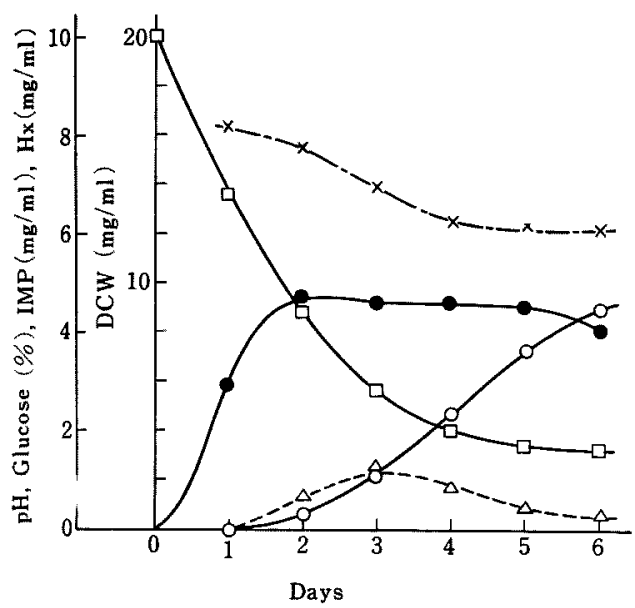

(A) KY 3482-9 (ad-).

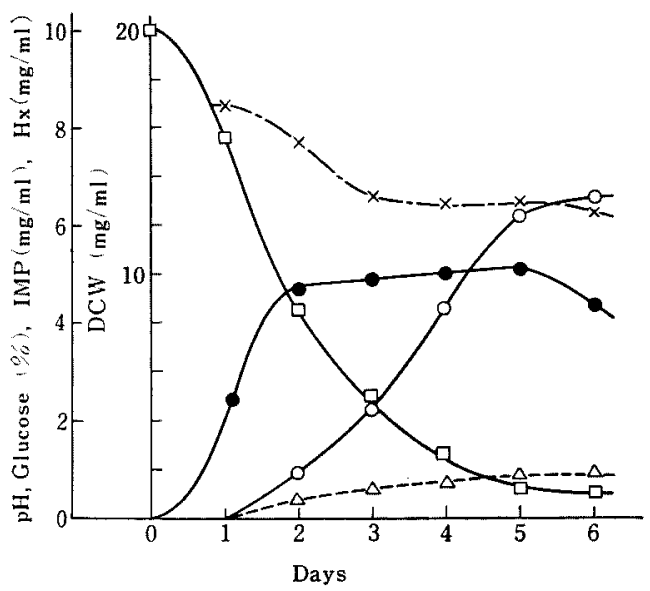

(B) KY 3482-9-54-252 (ad- Revertant).

derived from the adenine-guanine requiring mutants were cultured in the " $\mathrm{D}$ " medium supplemented with $150 \mu \mathrm{g} / \mathrm{ml}$ of adenine.

None of them produced a copious amount of guanine nucleotides, but the amounts of IMP accumulated were higher than those accumulated by a parent, KY $3482-9$ as shown in Fig. 2.

From the results the order of the IMP productivity of these mutants was shown as follows:

$$
\mathrm{Ad}^{-} \mathrm{Xa}^{-}>\mathrm{Ad}^{-} \text {Revertant }>\mathrm{Ad}^{-}
$$

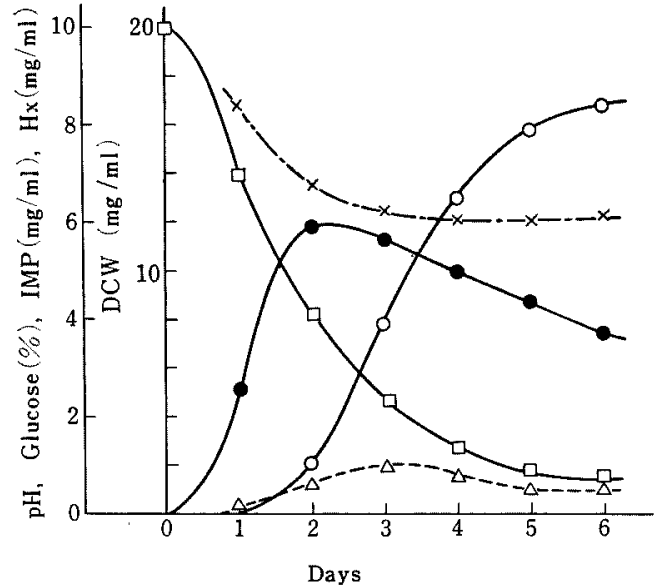

(C) KY 3482-9-54( ad- $\left.^{-} \mathrm{gu}^{-}\right)$.

FIG. 3. Time Courses of IMP Fermentation by Three Mutants of Brev. ammoniagenes.

Media: " $D$ " supplemented with $150 \mu \mathrm{g} / \mathrm{ml}$ of adenine for (A) and (B), and with $150 \mu \mathrm{g} / \mathrm{ml}$ of adenine and of guanine for $(\mathrm{C})$.

O-O IMP (mg/ml). $\quad \square-\square$ Glucose (\%).

$\triangle-\triangle \mathrm{Hx}(\mathrm{mg} / \mathrm{ml}) . \quad \times-x \quad \mathrm{pH}$.

-DCW $(\mathrm{mg} / \mathrm{ml})$.

Time courses of IMP fermentation by these mutants are shown in Fig 3. Although dried cell weights of both adenineless mutants, KY 3482-9 and KY 3482-9-54-252, were constant from 2 to 5-day of incubation, that of an adenine-guanine requiring mutant, KY 34829-54, was decreased gradually after 2 days of incubation.

\section{DISCUSSION}

Revertants (from $\mathrm{ad}^{-}+\mathrm{xa}^{-}$to $\mathrm{ad}^{-}$) of Brev. ammoniagenes did not accumulate a large amount of guanine nucleotides in the fermentation medium. This was different from the results obtained with Corynebacterium glutamicum. ${ }^{11}$

Possible reasons to explain the difference might be as follows: (1) difference of strains used, (2) IMP dehydrogenase of revertants was sensitive against GMP inhibition, (3) 
repression of this enzyme by guanine, (4) revertant was higher than that accumulated effect of cultural conditions and (5) degrada- by the parent strain. Activity of IMP dehytion of guanine nucleotides by phosphatases drogenase of the revertant may be changed or other enzymes.

However, the amounts of IMP produced by these mutants were increased markedly, since two enzymes, S.AMP synthetase and presumably IMP dehydrogenase, which catalyze two reactions from IMP to AMP and GMP were blocked by the mutation. It is interesting that the level of IMP accumulated by a by reversion.

It is concluded that these mutagenic treatments are effective to obtain a strain which accumulates larger amounts of IMP.

Acknowledgement. The authors are very grateful to Miss Y. Sato for her valuable technical assistance. 